\title{
DIAGNÓSTICO SOCIOAMBIENTAL DE MUNICÍPIOS COSTEIROS BASEADO EM UM SISTEMA DE INDICADORES
}

\section{ENVIRONMENTAL DIAGNOSIS OF COASTAL MUNICIPALITIES BASED ON A INDICATORS SYSTEM}

\author{
Vinícius Tischer \\ Universidade do Vale do Itajaí
}

\section{RESUMO}

A falta de indicadores socioambientais no Brasil tem sido um dos grandes desafios para a implementação de políticas públicas ambientais e urbana. Várias são as políticas incidentes no litoral que por meio dos seus instrumentos de gestão particularizam o processo de monitoramento como responsável por oportunizar o estado da qualidade ambiental e avaliar a melhoria da qualidade de vida da população. No entanto, diagnósticos ambientais suportados por um sistema robusto de indicadores não são uma realidade para muitos municípios costeiros, ainda que motivados pela apresentação do Relatório de Qualidade Ambiental como um instrumento do Plano Nacional do Gerenciamento Costeiro. O objetivo da pesquisa foi o de analisar a aplicabilidade de um sistema de indicadores socioambientais com base na aplicação deste em um estudo de caso tendo como referência geográfica os municípios de Penha, Itajaí e Balneário Camboriú, ambos situados no litoral centro-norte do estado de Santa Catarina. Os indicadores utilizados se deram em acordo com a seleção realizada no estudo de Tischer e Polette (2016). A partir disso, foram levantados dados para viabilizar a construção e validação dos indicadores através de diversas fontes e bancos de dados disponíveis. Como principal resultado tem-se a validação dos indicadores propostos. $O$ conjunto de indicadores ressalta com êxito as mudanças no uso do solo municipal frente a artificialização do solo e a degradação da qualidade ambiental e supressão de ecossistemas naturais.

Palavras-chave: Sistema de indicadores. Indicadores socioambientais. Zona Costeira. Gestão Costeira Integrada.

\begin{abstract}
The lack of socio-environmental indicators in Brazil has been one of the major challenges for implementation of urban and environmental public policies. Several policies have been applied to the coastal zone, which through their management tools, focus on the monitoring process as the factor responsible for providing environmental quality and improving the quality of life of the population. However, these tools do not clearly establish which environmental indicators can be adequately structured to form part of a subsequent Environmental Quality Report as an instrument of the National Coastal Management Plan. The purpose of the research was to analyze the applicability of a
\end{abstract}


system of environmental indicators based on the application of this in a case study having as geographical reference the municipalities of Penha, Itajaí and Camboriú, both located on the coast north-central state Santa Catarina. The indicators used were given in accordance with the selection made in the study of Tischer; Polette (2016). From this, it was raised data to enable the construction and validation of the indicator system through various sources and available databases. The main result has been the validation of the proposed indicators. The main result has been the validation of the proposed indicators. The set of indicators points out successfully the changes in the soil use and occupation of municipalities due to artificialization and the degradation of environmental quality and suppression of natural ecosystems.

Keywords: System of indicators. Socio-environmental indicators. Costal Zone. Integrated Costal Management.

\section{INTRODUÇÃO}

A região costeira é dotada de importância estratégica peculiar, que relaciona aspectos econômicos, ecológicos e socioculturais, como por exemplo: a pesca industrial, a logística estratégica portuária, as atividades do setor turístico e imobiliário; ecologicamente é ponto de transição na costa brasileira, sendo ainda área com influência cultural como é o caso da pesca artesanal.

Segundo MMA (2013), a Zona Costeira do Brasil é uma unidade territorial que se estende, na sua porção terrestre, por mais de $8.500 \mathrm{~km}$, abrangendo 17 estados e mais de quatrocentos municípios. A definição desta zona é estabelecida de acordo com os critérios do Decreto no $5.300 / 2004$, que regulamenta o Plano Nacional do Gerenciamento Costeiro. De acordo com o Art. $3^{\circ}$ a zona costeira brasileira, considerada patrimônio nacional pela Constituição de 1988, corresponde ao espaço geográfico de interação do ar, do mar e da terra, incluindo seus recursos renováveis ou não, abrangendo uma faixa marítima e uma faixa terrestre, sendo delimitado pelas faixas:

- faixa marítima: espaço que se estende por doze milhas náuticas, medido a partir das linhas de base, compreendendo, dessa forma, a totalidade do mar territorial;

- faixa terrestre: espaço compreendido pelos limites dos Municípios que sofrem influência direta dos fenômenos ocorrentes na zona costeira. 
Segundo o Projeto Orla o litoral de todo mundo tende a apresentar uma maior densidade demográfica que nos espaços interiores, e para o Brasil essa tendência ocorreu de forma pronunciada devido à ocupação se dar no sentido costa - interior, onde cerca de um terço da população habita a beira-mar e quase metade reside a menos de $200 \mathrm{~km}$ da costa (PROJETO ORLA, 2002).

Contudo, a zona costeira está entre os ambientes onde a pressão antropogênica é mais concentrada e onde os conflitos existentes e potenciais de uso da terra são mais críticos (PNUE, 2002). Isso se deve, conforme o Ministério do Meio Ambiente, justamente por esta zona representar também para as sociedades humanas pontos de intensa troca de mercadorias entre si, assim como pela exploração imprudente comprometendo por vezes a resiliência de seus recursos naturais (MMA, 2002). Assomado a isso, essas áreas representam o principal local de lazer, turismo ou moradia de grandes massas de populações urbanas, o que implica em perturbações ambientais durante o processo de ocupação humana, especialmente em regiões próximas aos grandes centros urbanos. Isso afeta diretamente os recursos naturais e a capacidade limitada desses de recomporem-se após impactos recebidos (ASMUS e KITZMANN, 2004).

Para identificar tendências emergentes na zona costeira e as consequências ambientais de tal processo de crescimento demográfico e urbanização, é necessário recolher informação relacionada aos diferentes aspectos do estado do ambiente urbano e de representá-los adequadamente, com a finalidade de sensibilizar as pessoas quanto à eficiência das políticas públicas, e servir de orientação aos planejadores de políticas, administradores e legisladores (CAMMARROTA e PIERANTONI, 2005). A Agenda 21 (MMA, 1992) aponta que indicadores de desenvolvimento sustentável precisam ser desenvolvidos para fornecer, bases sólidas para a tomada de decisões em todos os níveis e para contribuir para a autorregulação sustentável do meio ambiente e sistemas integrados de desenvolvimento.

Em contrapartida, observa-se que no Brasil, a falta de indicadores socioambientais tem sido um dos grandes desafios para as políticas públicas ambientais. Várias são as políticas públicas incidentes no litoral que por meio dos seus instrumentos de gestão particularizam o processo de monitoramento 
como o responsável por oportunizar o estado da qualidade ambiental e melhoria da qualidade de vida da população. Entre elas, o Plano de Gerenciamento Costeiro - PNGC (instituído pela Lei 7.661/1988 e regulamentado pelo decreto 5.300/2004) cita o Relatório de Qualidade Ambiental da Zona Costeira (RQA-ZC) como instrumento um instrumento do gerenciamento costeiro. No entanto, não estabelece quais indicadores socioambientais poderiam ser adequadamente estruturados para compor posteriormente um RQA.

Na prática, o que se observa é a ausência de um RQA-ZC, causada também, por decorrência da ausência de do Sistema de Monitoramento Ambiental da Zona Costeira que consiste no mecanismo de viabilização de dados e informações da zona costeira. Assim há a necessidade da utilização de indicadores socioambientais para um bom gerenciamento costeiro, e utilizando as informações que estes informam para a confecção de diagnósticos integrados em subsídio à tomada de decisões públicas.

Grande parte dos municípios não possuem suas políticas públicas pautadas em diagnósticos integrados da dinâmica socioeconômica e ambiental em seus territórios, desconhecendo as tendências e não identificando, prontamente, áreas de conflito ou de como proceder para a priorização de ações.

Um diagnóstico socioambiental integra os principais elementos de interação ambiental e da dinâmica populacional sobre o território, e assim permite a identificação das necessidades, problemas ambientais prioritários e suas respectivas causalidades, os vetores de pressão, os recursos e as potencialidades que constituem oportunidades de melhoria da qualidade ambiental e da qualidade de vida da população.

Em face da necessidade de conhecimento do território municipal e subsídio à tomada de decisão, foi motivado o desenvolvimento de pesquisa de mestrado acerca da aplicabilidade de um sistema de indicadores baseado em um sistema de referência.

O presente trabalho está integrado ao projeto Análise da Biodiversidade como componente da Ecologia da Paisagem dos Promontórios Costeiros da região Centro-norte de Santa Catarina vinculada à Fundação de Apoio à 
Pesquisa Científica e Tecnológica do Estado de Santa Catarina - FAPESC, tendo como linha de pesquisa a proposição de indicadores socioambientais aplicados nos municípios costeiros do litoral centro norte de Santa Catarina, com ênfase nos promontórios costeiros.

Sob essa perspectiva, umas das instituições de referência é o Observatório do Litoral Francês (Observatorie National de la Mer et du Littora). Sua finalidade é coletar, compilar, tratar e sintetizar os vários dados disponíveis sobre a costa. Este instituto orientar na escolha de indicadores, na apropriação dos resultados por parte dos atores e fornece informações para subsidiar gestores públicos (ONML, 2012).

Nesse sentido, o objetivo do projeto foi avaliar o estado socioambiental de municípios costeiros baseado em um sistema de indicadores ambientais do Observatório do Litoral Francês, utilizando como estudo de caso, os municípios de Penha, Itajaí e Balneário Camboriú, localizados no litoral centro norte de Santa Catarina.

A proposta busca trazer uma alternativa de diagnóstico socioambiental voltado para a aplicação de indicadores. Estes possuem o foco de mensuração da dinâmica demográfica e urbana e sua interação com o meio ambiente, para que seja passível informar a população do município, de forma simplificada e didática, sobre o status da qualidade socioambiental dos ecossistemas, e as relações da gestão pública na dinâmica territorial.

\section{MATERIAIS E MÉTODOS \\ Área de estudo}

A área de estudo consiste nos município de Balneário Camboriú, Itajaí e Penha, localizados no litoral centro norte de Santa Catarina pertencentes à microrregião de Itajaí e mesorregião do Vale do Itajaí.

A escolha destes municípios se deu devido à proposta inicial de trabalho estar vinculado a projeto da Fundação de Apoio e Pesquisa e Inovação do Estado de Santa Catarina - FAPESC sobre análise da paisagem que tinha como área de estudo as referências geográficas dos promontórios costeiros do 
litoral centro-norte de Santa Catarina, especificamente na Morraria da Praia Vermelha (município de Penha); a morraria do Farol de Cabeçudas (município de Itajaí) e a Área de Proteção Ambiental Costa Brava (município de Balneário Camboriú), devido à alta importância para a conservação destas áreas.

Em contrapartida, o escopo do projeto foi ampliado para todo o município, com exceção de alguns indicadores, devido a limitações no projeto. As áreas dos municípios e dos promontórios costeiros são mostradas na Figura 1.

Figura 1: Localização dos municípios de estudo com ênfase nos promontórios costeiros

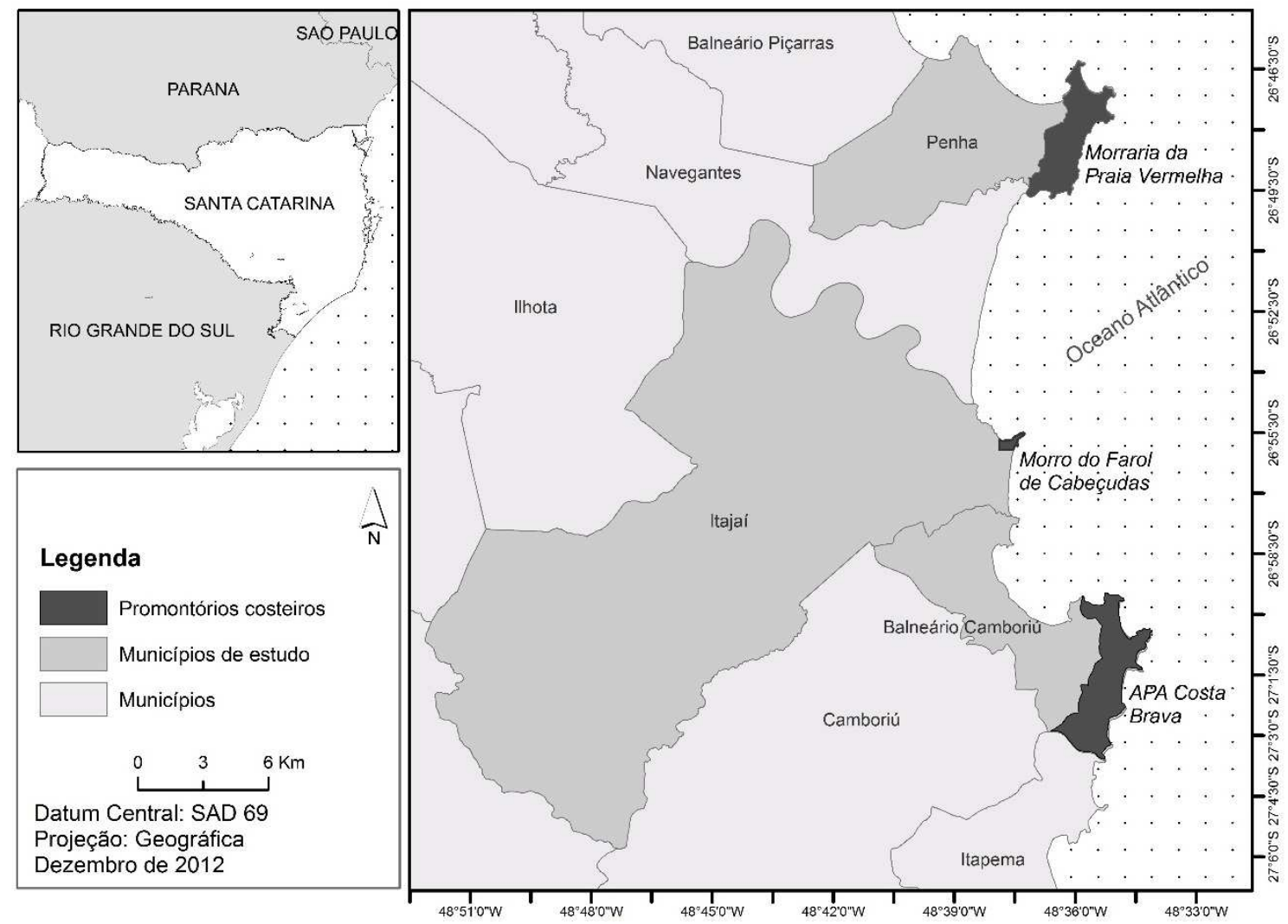

\section{Sistema de Indicador}

$\mathrm{Na}$ fase inicial de pesquisa foi realizada a determinação do sistema de indicadores utilizados, por meio de uma adequação do sistema de indicadores do Observatório do Litoral Frances para a realidade brasileira. A metodologia utilizada e os resultados das ponderações da seleção são apresentados em 
Tischer e Polette (2016) e o rol de indicadores determinados é apresentado na Tabela 1.

Tabela 1: Sistema de indicadores utilizados no estudo

\begin{tabular}{ll}
\hline \multicolumn{1}{c}{ Tema } & \multicolumn{1}{c}{ Sistema de Indicadores } \\
\hline $\begin{array}{l}\text { Natureza e } \\
\text { biodiversidade }\end{array}$ & $\begin{array}{l}\text { Ambiente natural das cidades litorâneas } \\
\text { Proteção da natureza } \\
\text { Lugares protegidos segundo o MMA }\end{array}$ \\
\hline $\begin{array}{ll}\text { População e } \\
\text { demografia }\end{array}$ & $\begin{array}{l}\text { Densidade populacional das cidades litorâneas } \\
\text { Tendências da evolução da população }\end{array}$ \\
\hline $\begin{array}{l}\text { Qualidade da } \\
\text { água }\end{array}$ & Qualidade das águas do mar \\
\hline Riscos & Erosão costeira no litoral \\
\hline Uso do solo & População total presente no município \\
\hline
\end{tabular}

Fonte: TISCHER e POLETTE, 2016.

\section{Aplicação de Indicadores}

A partir da determinação do sistema de indicadores, os indicadores foram construídos com dados referentes aos municípios ou em alguns casos para áreas menores (promontórios costeiros), dependendo da disponibilidade dos dados. Os indicadores desenvolvidos apenas para as áreas dos promontórios são relativos aos temas: Natureza e Biodiversidade; e Qualidade da água (vide Tabela 1).

Cada sistema-indicador foi organizado em uma ficha de indicadores, as quais se utilizaram de tabelas, gráficos e mapas a fim de facilitar a interpretação dos dados levantados, assim como, facilitar a compreensão dos indicadores enquanto instrumento de comunicação com a sociedade civil e 
tomadores de decisão, potencializando a divulgação e popularização do uso de indicadores.

Cada ficha contém a descritiva para cada sistema de indicadores, e é estruturada da seguinte forma:

a) Data de elaboração do indicador;

b) Contexto (introdução sobre o tema);

c) Objetivo dos indicadores gerados;

d) Definições e metodologia;

e) Área geográfica;

f) Unidade de medida;

g) Afinidade com a sustentabilidade (qual a relação e importância dos indicadores com a questão da sustentabilidade);

h) Metas a alcançar (valores de referência a serem atingidos pelos indicadores enquanto ferramenta de gestão pública)

i) Periodicidade;

j) Fontes de dados;

k) Discussão e resultados e;

I) Referências bibliográficas.

A avaliação do estado das áreas analisadas foi feita tendo como base o sistema de indicadores presente nas fichas de indicadores, relacionando 0 objetivo de cada indicador e suas implicações e importância para 0 gerenciamento da área de estudo. Uma vez aplicados, os indicadores proporcionaram uma discussão integrada de como a variável estudada se manifesta no território, e que conclusões são importantes a serem consideradas para a gestão e governança municipal.

A construção dos indicadores é baseada na compilação de dados e informações. Alguns indicadores demandaram dados primários (e.g. pesquisa de campo). E outros, de forma secundária (bases de dados do IBGE, ministérios federais, secretarias municipais, sindicatos, órgãos de meio ambiente e pesquisadores locais). Um detalhamento maior dos indicadores utilizados no presente estudo é mostrado na Tabela 2. Esta compilação reúne a descrição de quais indicadores foram empregados tendo sido utilizados um indicador para cada sistema. 
Tabela 2: Sistema de indicadores utilizados, com respectivos conceitos, objetivos, unidade, fórmulas e a referência dos dados utilizados

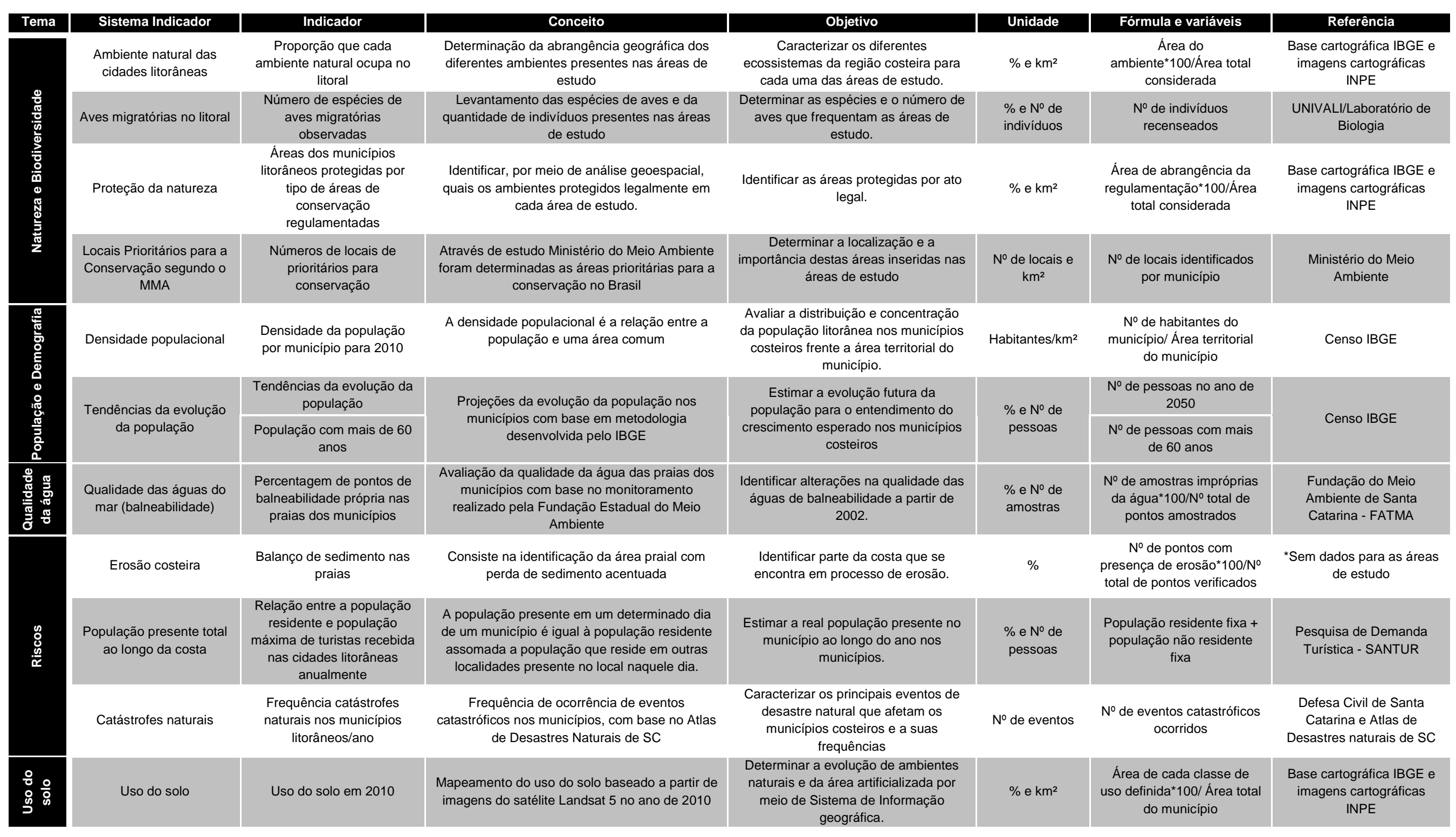




\section{Sistema DPSIR}

A utilização do modelo DPSIR tem por objetivo de adequar os indicadores dentro de um relatório de qualidade, constituíndo em uma estrutura de qualificação dos indicadores acerca de suas características de força motriz, pressão, estado, impacto e resposta.

Dessa forma, após a análise do modelo de indicadores, todos os indicadores, com exceção dos que não foram considerados relevantes para a agenda, segundo o conceito de Jannuzzi (2006) formam elencados e classificados utilizando a seguinte estrutura:

- Força motriz: indicadores que refletem os fatores responsáveis pelas pressões no meio ambiente;

- Pressão: indicadores que avalia resultantes das atividades humanas que causam ou podem causar problemas ambientais;

- Estado: indicadores de estado descrevem o estado de vários aspectos do ambiente, em determinado momento. $O$ estado também depende das condições naturais, as pressões sobre o meio ambiente e medidas de protecção ambiental foram implementadas;

- Impacto: indicadores de impacto mostrar as consequências das mudanças no estado do ambiente ou a população;

Resposta: indicadores que refletem iniciativas da sociedade e de gestão para melhorar os problemas ambientais.

\section{RESULTADOS}

Apesar da viabilidade de construção da maioria dos indicadores, alguns não foram possíveis de construção, visto a ausência de dados para os municípios. Como é o caso do: Balanço de sedimentos nas praias; e Aves migratórias para o município de Balneário Camboriú.

Os resultados dos indicadores foram compilados na Tabela 1, permitindo uma análise comparativa entre os municípios de estudo além de expressar o significado prático da aplicação dos indicadores na gestão pública municipal. 
Reitera-se ainda, que esta análise apresenta-se de uma forma sintetizada das fichas de indicadores desenvolvidas.

\section{Natureza e Biodiversidade}

No que se refere à proporção que cada ambiente natural ocupa no litoral, observa-se que mais de três quartos dessas áreas são ocupadas por ambientes sem interferência antropogênica. Os dados para esses indicadores foram determinados somente para as áreas de estudo. Na APA da Costa Brava, essa proporção atinge 87\%, Morraria da Praia Vermelha $85 \%$ e Farol de Cabeçudas $74 \%$. Como observado nas figuras abaixo, o ambientes de estudo possuem características de alta relevância ambiental e ecológica com características pristinas em alguns pontos, como é o caso da praia de Taquarinhas (Figura 1.) onde a restinga encontra-se em estágio arbóreo e sem a presença de interferências antrópicas. Na Costa Brava 96\% do território possuem áreas protegidas, sendo $39 \%$ devido a leis municipais e $57 \%$ devido a legislações ambientais federais.

Destaca-se que durante os procedimentos de quantificação das áreas de protegidas (APP, UC ou proteção especial por lei municipal) por vezes acontecem sobreposição dessas áreas, por exemplo: APP de rios pode contemplar manguezal, mas para efeito de contabilização de área total protegida, esse efeito não é relevante.

Da mesma forma, quando é analisada as áreas dos municípios protegida por instrumentos legais, observa-se que na morraria da Praia Vermelha (Figura 2), aproximadamente $86 \%$ do território está sob o domínio de leis de proteção ambiental, sendo $27 \%$ por leis municipais e $59 \%$ pela legislação federal 
Figura 1: Vista geral da praia de Taquarinhas na APA da Costa Brava Balneário Camboriú (SC)

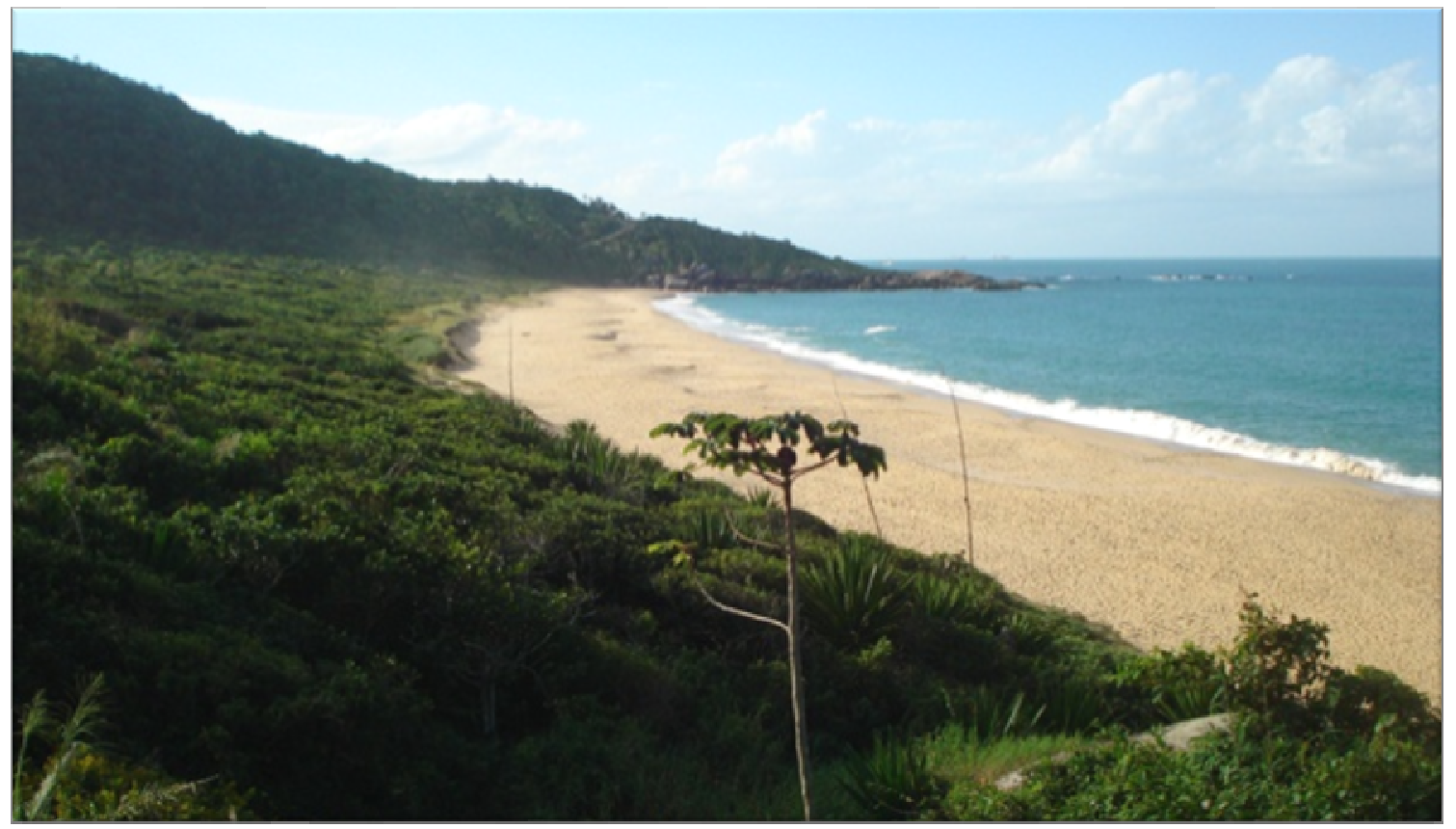

Figura 2: Vista geral da praia Vermelha na Morraria da Praia Vermelha, Penha (SC)

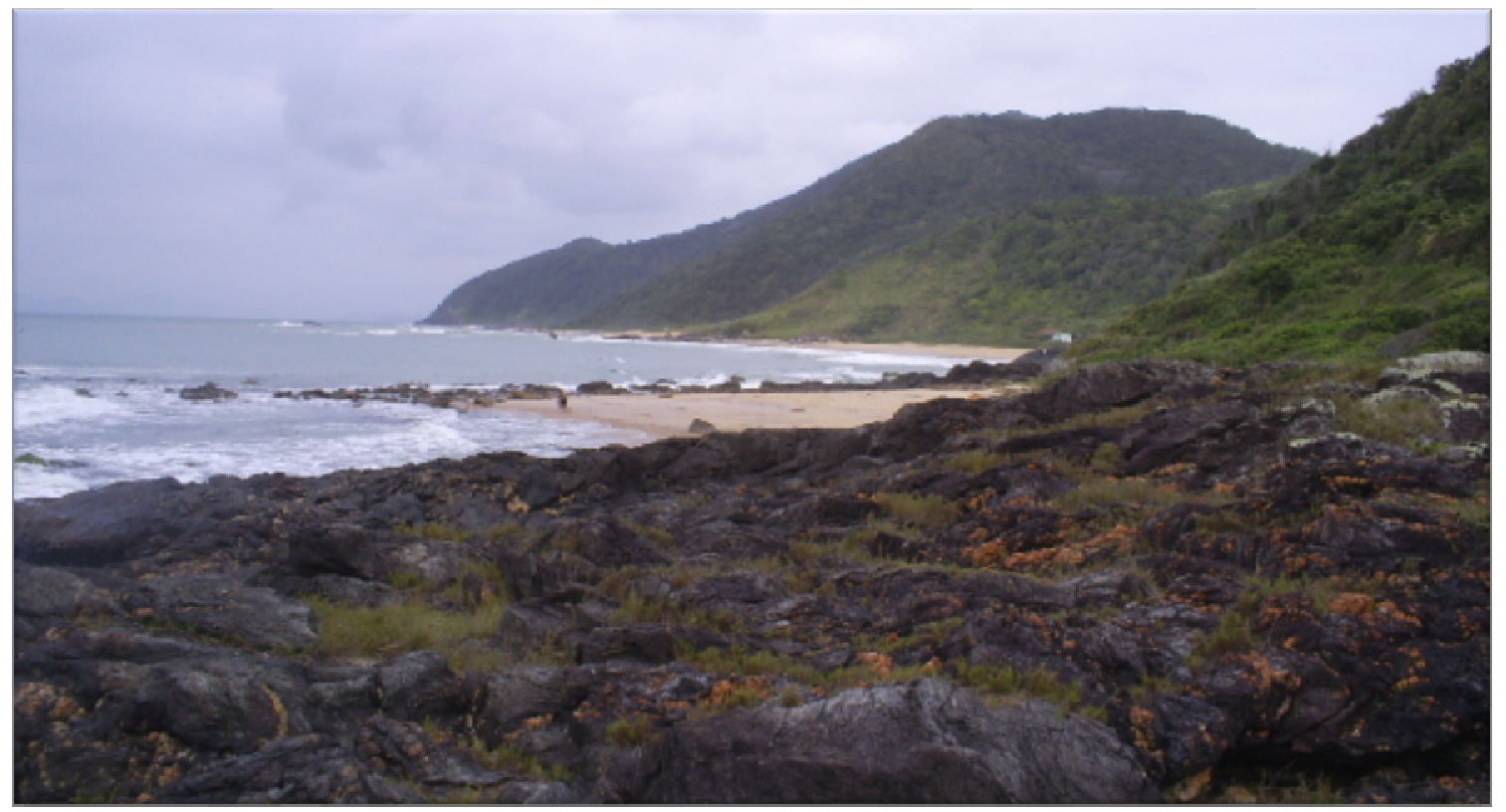

Para o município de Itajaí, a área compreendida pelo Morro do Farol de Cabeçudas (Figura 3.) (por ser uma área muito pequena comparada com as 
outras) encontra-se $100 \%$ protegida por leis, sendo $50 \%$ pela legislação municipal e $50 \%$ por leis federais.

Cabe ressaltar que, tanto o indicador: Proporção que cada ambiente natural ocupa no litoral, como: Áreas dos municípios litorâneos protegidas por tipo de áreas de conservação regulamentadas, por serem desenvolvidos em áreas geográficas relativamente pequenas quando comparado com o município total sofrem de um efeito que mascara as proporções existentes para todo município. Por exemplo, a proporção de espaços naturais na área dos promontórios é alta (acima de 75\%), mas quando comparado com o município total, essa proporção diminuiria consideravelmente.

Figura 3: Vista geral do promontório do Farol de Cabeçudas. Itajaí (SC)

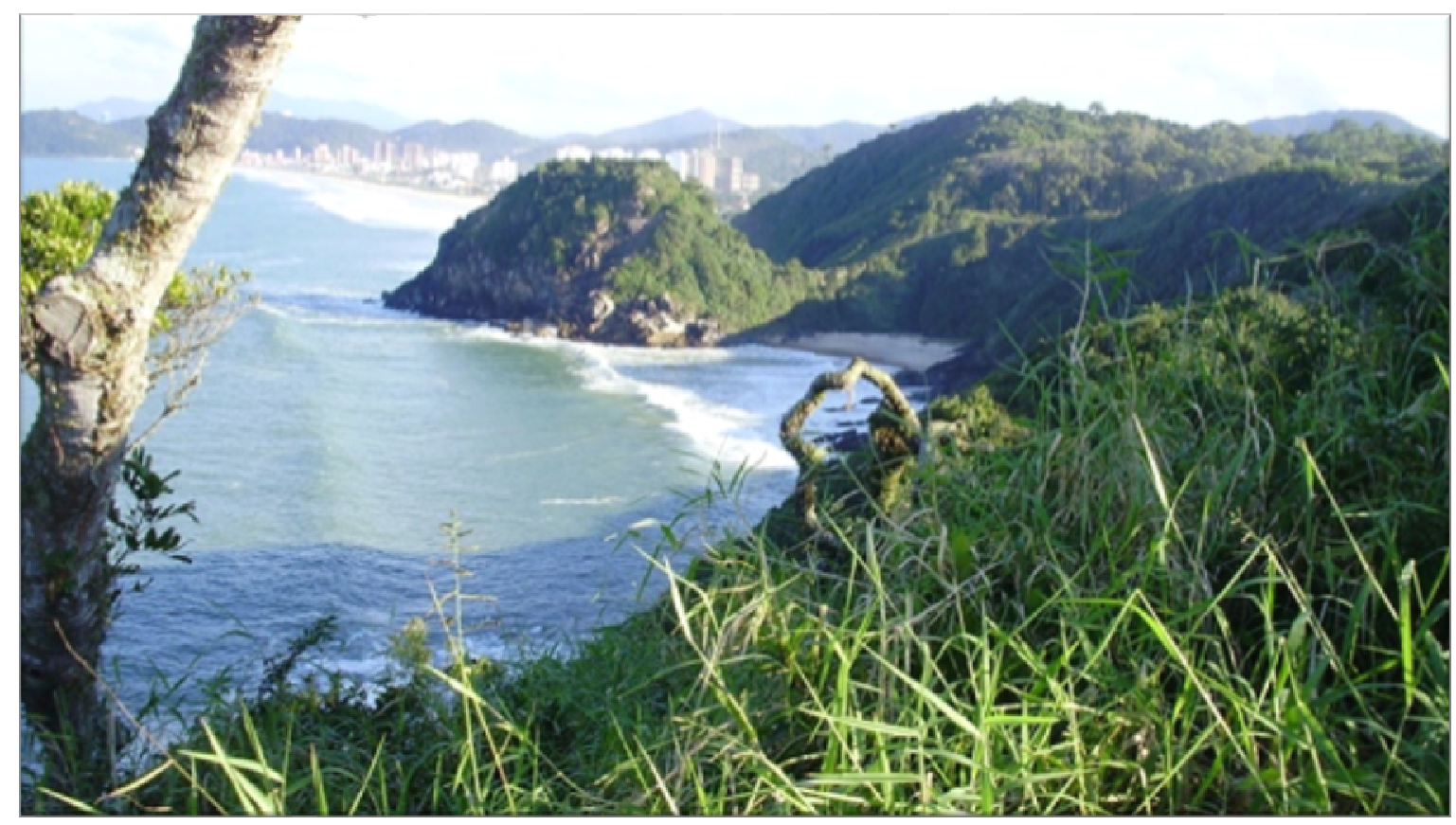

O resultado dos indicadores alerta para a necessidade estratégica de implantação de Unidades de Conservação nestas áreas. Com um aumento das áreas protegidas eficazmente implantadas, os diversos serviços ambientais prestados pela área seriam potencializados. Além disso, impactos socioeconômicos poderiam ser potencializados, como a exploração turística da área, baseado em Planos de Manejo bem estruturados.

Ainda, se observam que em todos os municípios, há a presença de locais consideradas pelo Ministério do Meio Ambiente (MMA) como prioritários para a 
conservação. Essas áreas possuem características ecológicas e ambientais singulares e são tidas como muito importante para a preservação da biodiversidade. Quanto ao sistema-indicador: Proteção da natureza é possível evidenciar a importância do alvo de políticas públicas de conservação tanto para a proteção da biodiversidade como para a manutenção dos serviços ambientais.

Outro indicador se refere à análise sobre as aves migratórias no litoral. Quando analisado especificamente sobre o número de espécie de aves observadas, há uma lacuna quanto à geração de dados censitários de aves. Os dados quantitativos de aves utilizados para Penha são referentes a coletas realizadas no município de Barra Velha e para Itajaí utilizou-se dados coletados na zona estuarina do município, Para o município de Balneário Camboriú, entretanto, não foi possível obter dados quantitativos monitorados.

Levantamentos realizados por Branco et. al. (2004), por meio de 28 campanhas efetuadas em um ano, registram a presença de 189 aves migratórias em Barra Velha, e 502 na região de Itajaí.

\section{População e Demografia}

Segundo Belfiori (2003) $50 \%$ da população mundial habita a zona costeira (20\% da superfície do planeta) o que representa uma densidade média de 80 $\mathrm{hab} / \mathrm{km}^{2}$, o dobro da média global. Nos municípios de estudo constatou-se uma densidade demográfica alta, superior à média nacional de 22,43 hab/km² (IBGE, 2010).

Entre os três municípios, Penha possui a menor densidade, com $406 \mathrm{hab} / \mathrm{km}^{2}$, seguido de Itajaí com $634 \mathrm{hab} / \mathrm{km}^{2}$. Já o município de Balneário Camboriú apresenta uma densidade demográfica muito superior, com 2.310hab/km², considerada também a maior de Santa Catarina.

Merece destaque ainda a projeção da população para um horizonte temporal futuro. Para o ano de 2050, a tendência é o crescimento populacional para os municípios de Penha, Itajaí e Balneário Camboriú. Esta ocorre com uma taxa de $40 \%, 26 \%$ e $43 \%$, respectivamente. Esse crescimento populacional 
imporá em risco de aumento de conflitos no uso e ocupação do solo e de recursos naturais, devido ao maior número de pessoas no território.

Conforme mostram os indicadores, com as taxas de crescimento populacional positivas, a densidade nos três municípios tenderá a aumentar. Dessa forma, um maior consumo de recursos e espaços artificializados para infraestrutura serão demandados. Isso implicará no aumento de efluentes sanitários, resíduos sólidos e outras perturbações ambientais, comprometendo a qualidade e o conforto ambiental, caso seja extrapolado a capacidade de carga das estruturas de manejo e dos próprios recursos naturais. Apenas em torno do ano de 2040, segundo projeções, a população entrará em processo de estabilização.

Quando se observa o crescimento populacional estratificado por faixas etárias, o aumento será ainda mais pronunciado sob a população idosa. Sendo que esta classe de idade (população com mais de 60 anos) encontra-se em processo de envelhecimento. Enquanto no ano de 2010, essa faixa etária correspondia a aproximadamente $12 \%$ da população de Penha e Balneário Camboriú e 9\% em Itajaí, estimativas para o ano de 2050 apontam que essa população atingirá cerca de $58 \%$ da população do município de Penha, $34 \%$ em Itajaí e $60 \%$ em Balneário Camboriú. O que caracteriza uma transição etária completa da população para o seu envelhecimento.

Essa mudança na pirâmide etária brasileira, conforme explicada pelo IBGE (2008) se dá devido à queda no número de nascimentos anualmente, desde a década de 1960, juntamente com os avanços na medicina que aumentam a esperança de vida ao nascer e diminuem a taxa de mortalidade.

\section{Qualidade da água}

Quanto à balneabilidade da água do mar nas áreas analisadas foi identificado que a melhor qualidade da água nos pontos de coleta está no município de Penha, com a percentagem de pontos de balneabilidade próprios nas praias do município foi de $95 \%$ de todas as amostras de água realizadas desde 2002 até 2011. Em Itajaí e Balneário Camboriú, entretanto, observa-se uma qualidade adequada da água acontece em apenas em dois terços das 
análises procedidas (respectivamente $61,5 \%$ e $64 \%$ ). Cabe ressaltar que 0 monitoramento da FATMA leva em conta apenas o parâmetro microbiológico: coliformes termotolerantes, que podem ser relacionados diretamente com lançamentos de esgotos sanitários.

\section{Riscos}

Estudos sobre o balanço de sedimentos nas praias/ erosão costeira, especificamente nas áreas de estudo, não foram encontrados, apesar de estes existirem em outras localidades próximas dos municípios analisados, como por exemplo: Menezes (2008) na praia Central de Balneário Camboriú; e MMA (2007) em Barra Velha, Piçarras e Navegantes.

Outra análise se refere ao indicador: população real presente no município, ou seja, o balanço resultante das pessoas que se deslocam de um município para outro. Esses remetem a relação entre a população residente e a população máxima de turistas e/ou veranistas recebida nas cidades litorâneas por ano, e são fornecidos pela pesquisa de demanda turística feita pela SANTUR (2005 a 2009).

Segundo a pesquisa para o município de Penha ocorreu apenas durante o período de veraneio. Para Itajaí e Balneário Camboriú existe disponível uma série anual, de 2008 a 2009 para Itajaí, e 2010 em Balneário Camboriú. Entretanto para ambas, as pesquisas não abordam uma estimativa da população que deixa o município.

O município de Penha, na época de veraneio, revelou a presença de uma população máxima de $352 \%$, ou seja, aproximadamente 3,5 vezes a população residente fixa. Em Itajaí a pesquisa revelou que a população máxima atinge $136 \%$ da população fixa e mínima de $123 \%$.

Em Balneário Camboriú, a população máxima atinge 857\% (janeiro de 2010) acima do valor de sua população residente fixa, e a mínima de $230 \%$ (setembro de 2010). Dessa forma, é possível concluir que mesmo em períodos de inverno, uma quantidade superior de pessoas que exercem pressão sobre os recursos ambientais e na infraestrutura urbana. Assim, para questões de 
planejamento urbano, a população flutuante presente no município deve ser criteriosamente analisada para que estimativas de demanda de infraestrutura não sejam subestimados (SANTUR, 2010).

O último sistema-indicador inserido no tema riscos refere-se às catástrofes naturais ocorridas nos municípios ao longo do ano. Tendo como exemplo as inundações graduais, as compilações realizadas por Hermann (2007) fornecem dados em faixas de frequência do evento em uma série histórica entre 1980-2004. Para o município de Penha foi identificado no período apenas um evento, em Itajaí entre 09 e 20 eventos e em Balneário Camboriú entre 2 e 4 eventos.

O município de Itajaí possui um histórico de grandes inundações com destaque para os anos de 1983, 2008 e 2011. Essas catástrofes afetam grande parte da superfície do município, merecendo destaque quanto às orientações nas tomadas de decisões públicas no município, no uso e ocupação do solo, e na reabilitação das áreas de várzea, e na criação de espaços verdes.

Dessa forma, é preciso levar em conta que o litoral possui problemas particulares, sujeito a vários riscos naturais pela incerteza devido as proximidade com o mar, como por exemplo, elevação do nível do mar, tempestades, erosão da linha da costa, etc. Juntamente a isso os municipios costeiros abrigam parte consideravel da população. Em Santa Catarina, de acordo com o censo 2010 (IBGE), 1.734 .904 pessoas vivem ao longo dos 29 municípios costeiros ( $28 \%$ da população fixa do estado), excluindo-se ainda os milhares de turistas presentes em épocas de veraneio.

\section{Uso do solo}

Os municípios em estudo possuem ainda uma evidente tendência de expansão urbana, assim como de adensamento e verticalização, sendo Balneário Camboriú o município em que este grau de urbanização se encontra em estágio mais avançado. Para a comparação da artificialização do território nos municípios, o uso do solo revela que o município de Penha, em 2010, possuía 21\% do território artificializado; Itajaí 19\%; e Balneário Camboriú 39\%. 
O resultado sintetizado dos indicadores pode ser observado na Tabela 3, contendo uma referência aos indicadores e seus respectivos sistemas e temas. A tabela permite a comparação entre os três municípios estudados. Esta, entretanto, apresenta uma compilação dos indicadores, sendo apresentado apenas um indicador para cada sistema-indicador.

Mediante análise realizada, foi possível elencar os fatores críticos nos municípios de estudo que constituem fatores de pressão sobre a qualidade ambiental (Tabela 4).

Nota-se que para ambos os municípios, o crescimento populacional e suas implicações representam fatores críticos, uma vez que geram maiores cargas poluidoras, além da demanda de novas áreas de assentamentos em detrimento a ambientes naturais.

Em Itajaí ressalta-se a presença de catástrofes naturais (sobretudo inundações) que prejudicam o desenvolvimento do município, fornecem risco à saúde pública. Outra manifestação destes eventos é que a população mais afetada é a que possui maior vulnerabilidade social, que possuem condições restritas financeiras, ocupando por vezes áreas de várzea sujeitas a inundações.

O município de Balneário Camboriú destaca-se pela verticalização e artificialização de seu território. Apesar de contar com ambientes naturais na região das Praias Agrestes, inclusive locais prioritários para a conservação, a zona central possui elevada densidade, com pouca quantidade de áreas permeáveis e mínimas áreas vegetadas tampouco, parques urbanos. 
Tabela 3: Comparativo entre os municípios em estudo: Penha, Itajaí e Balneário Camboriú

\begin{tabular}{|c|c|c|c|c|c|}
\hline Tema & Sistema Indicador & Indicador & Penha & Itajaí & Balneário Camboriú \\
\hline \multirow{5}{*}{$\begin{array}{l}\text { Natureza e } \\
\text { biodiversidade }^{1}\end{array}$} & $\begin{array}{l}\text { Ambiente natural das cidades } \\
\text { litorâneas }\end{array}$ & $\begin{array}{l}\text { Proporção que cada ambiente natural ocupa no } \\
\text { litoral }\left(\mathrm{km}^{2}\right)\end{array}$ & $85 \%$ & $75 \%$ & $87 \%$ \\
\hline & Aves migratórias no litoral & $\begin{array}{l}\text { Número de espécies de aves migratórias } \\
\text { observadas }\end{array}$ & $189 / \mathrm{ano}^{2}$ & $502 /$ ano $^{3}$ & Sem dados \\
\hline & \multirow[t]{2}{*}{ Proteção da natureza } & \multirow[t]{2}{*}{$\begin{array}{l}\text { Áreas dos municípios costeiros protegidas por } \\
\text { tipo de áreas de conservação regulamentadas }\end{array}$} & $\begin{array}{l}\text { Legislação Municipal (Plano } \\
\text { diretor) })^{1}: 27 \%\end{array}$ & $\begin{array}{l}\text { Legislação Municipal (Plano } \\
\text { diretor) })^{1}: 50 \%\end{array}$ & $\begin{array}{l}\text { Legislação Municipal (Plano } \\
\text { diretor) })^{1}: 39 \%\end{array}$ \\
\hline & & & Legislação Federal: 59\% & Legislação Federal: 50\% & Legislação Federal: 57\% \\
\hline & $\begin{array}{l}\text { Lugares protegidos segundo o } \\
\text { Ministério do Meio Ambiente }\end{array}$ & $\begin{array}{l}\text { Números de locais de prioritários para } \\
\text { conservação (segundo MMA) }\end{array}$ & Morraria Penha & Farol de Cabeçudas & Promontórios Costa Brava \\
\hline \multirow{3}{*}{$\begin{array}{l}\text { População e } \\
\text { Demografia }\end{array}$} & Densidade populacional & $\begin{array}{l}\text { Densidade da população por município para } \\
\qquad 2010\end{array}$ & $406 \mathrm{hab} / \mathrm{km}^{2}$ & $634 \mathrm{hab} / \mathrm{km}^{2}$ & $2.310 \mathrm{hab} / \mathrm{km}^{2}$ \\
\hline & \multirow{2}{*}{$\begin{array}{l}\text { Tendências da evolução da } \\
\text { população }\end{array}$} & $\begin{array}{l}\text { Tendências da evolução da população para os } \\
\text { anos de } 2050 \text {. }\end{array}$ & Incremento em $40 \%$ & Incremento em $\quad 26 \%$ & Incremento em $43 \%$ \\
\hline & & População com mais de 60 anos em 2010 & $12,1 \%$ & $8,9 \%$ & $11,8 \%$ \\
\hline \multirow[t]{2}{*}{ Qualidade da água } & $\begin{array}{l}\text { Qualidade das águas do mar } \\
\text { (balneabilidade) }\end{array}$ & $\begin{array}{l}\text { Percentagem de pontos de balneabilidade } \\
\text { própria nas praias dos municípios (2011) }\end{array}$ & $95 \%$ própria & $61,55 \%$ própria & $64 \%$ própria \\
\hline & Erosão costeira & Balanço de sedimento nas praias & Sem dados & Sem dados & Sem dados \\
\hline \multirow[t]{2}{*}{ Riscos } & $\begin{array}{l}\text { População presente total ao longo } \\
\text { da costa }\end{array}$ & $\begin{array}{l}\text { Relação entre a população residente e } \\
\text { população máxima de turistas e/ou veranistas } \\
\text { recebida nas cidades litorâneas/ano }\end{array}$ & $\begin{array}{l}\text { População máxima: } 352 \% \\
\text { (2008); população mínima: } \\
\text { sem dados }\end{array}$ & $\begin{array}{l}\text { População máxima: } 123 \% \text {; } \\
\text { população mínima: } 136 \% \\
\text { (2008-2009) }\end{array}$ & $\begin{array}{l}\text { População máxima: } 857 \%: \\
\text { população mínima:230\% (2010) }\end{array}$ \\
\hline & Catástrofes naturais & $\begin{array}{l}\text { Frequência catástrofes naturais nos municípios } \\
\text { litorâneos/ano }\end{array}$ & $\begin{array}{l}1 \\
\text { (média entre } 1980-2006 \text { ) }\end{array}$ & $\begin{array}{c}14,5 \\
\text { (média entre } 1980-2006 \text { ) }\end{array}$ & $\begin{array}{c}3 \\
\text { (média entre } 1980-2006 \text { ) }\end{array}$ \\
\hline Uso do solo & Uso do solo & Uso do solo em 2010 (\%) & Grau de artificialização: 21\% & Grau de artificialização: 19\% & Grau de artificialização: 39\% \\
\hline
\end{tabular}

\footnotetext{
${ }^{1}$ Este tema refere-se as áreas que abrangem os promontórios costeiros dos municípios em estudo, e não todo município

2 Coleta de dados realizados no município de Barra Velha, ao norte de Penha

${ }^{3}$ Coleta realizada no Saco da Fazenda (região do município de Itajaí)
} 
Tabela 4: Pontos críticos identificados nos municípios de estudo

\begin{tabular}{|c|c|c|}
\hline \multicolumn{3}{|c|}{ Pontos Críticos } \\
\hline Penha & Itajaí & Balneário Camboriú \\
\hline $\begin{array}{l}\text { - Incremento populacional } \\
\text { que contribui para o } \\
\text { desmatamento de novas } \\
\text { áreas e a geração de } \\
\text { resíduos e efluentes } \\
\text { ameaçam os } \\
\text { ecossistemas naturais; } \\
\text { - Locais prioritários para a } \\
\text { conservação } \\
\text { pressionados } \\
\text { urbanização }\end{array}$ & $\begin{array}{l}\text { - A qualidade da água nas } \\
\text { praias está comprometida } \\
\text { em grande parte do tempo, } \\
\text { resultado da deficiência do } \\
\text { saneamento básico; } \\
\text { - Alto nível de catástrofes } \\
\text { naturais é observado, } \\
\text { incidentes principalmente } \\
\text { pela localização da cidade } \\
\text { em áreas de várzea; } \\
\text { - Locais prioritários para a } \\
\text { conservação pressionados } \\
\text { pela urbanização }\end{array}$ & $\begin{array}{l}\text { - Densidade demográfica e } \\
\text { incremento populacional } \\
\text { contribuem para a } \\
\text { necessidade de novas } \\
\text { terras e geração de } \\
\text { resíduos e efluentes; } \\
\text { - A qualidade da } \\
\text { balneabilidade das águas } \\
\text { em alguns pontos está } \\
\text { comprometida } \\
\text { - A artificialização do } \\
\text { município ameaça a } \\
\text { supressão de ecossistemas } \\
\text { naturais; } \\
\text { - Locais prioritários para a } \\
\text { conservação pressionados } \\
\text { pela urbanização }\end{array}$ \\
\hline
\end{tabular}

\section{Aplicação dos indicadores no modelo DPSIR}

Essa análise permite identificar os indicadores que integram processos de: força motriz, pressão; estado; impacto e resposta, e suas inter-relações, como mostra a Tabela 5 e Figura 6 . Os indicadores desenvolvidos constituemse por indicadores de estado ( 3 indicadores), de pressão ( 3 indicadores), de resposta ( 3 indicadores) e de indicadores de impacto (2 indicadores). Como indicadores de força-motriz, foi considerado o indicador densidade demográfica. 
Tabela 5: Indicadores desenvolvidos aplicados ao modelo DPSIR

\begin{tabular}{|c|c|c|c|c|c|c|c|}
\hline Tema & $\begin{array}{l}\text { Sistema } \\
\text { Indicador }\end{array}$ & Indicador & 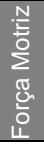 & $\begin{array}{l}0 \\
\text { ing } \\
0 \\
0 \\
0 \\
0 \\
\end{array}$ & $\begin{array}{l}\frac{0}{0} \\
\frac{\pi}{5} \\
w\end{array}$ & $\begin{array}{l}\text { 을 } \\
\text { 을 } \\
\text { 트 } \\
\end{array}$ & $\begin{array}{l}\frac{\pi}{0} \\
\frac{0}{0} \\
\frac{0}{0} \\
0 \\
\frac{1}{\simeq}\end{array}$ \\
\hline \multirow{11}{*}{$\begin{array}{l}\text { Natureza e } \\
\text { biodiversidade }\end{array}$} & \multirow{3}{*}{$\begin{array}{l}\text { Ambiente } \\
\text { natural das } \\
\text { cidades } \\
\text { litorâneas }\end{array}$} & Número e de habitats costeiros por município do litoral & & & & & \\
\hline & & Proporção que cada ambiente natural ocupa no município & & & & & \\
\hline & & Nível de presença dos ambientes no litoral & & & & & \\
\hline & \multirow{3}{*}{$\begin{array}{l}\text { Aves } \\
\text { migratórias }\end{array}$} & $\begin{array}{l}\text { Porcentagem de espécies migratórias de ocorrência no litoral } \\
\text { centro-norte de SC }\end{array}$ & & & & & \\
\hline & & $\begin{array}{l}\text { Número de indivíduos de aves migratórias observadas próximas às } \\
\text { áreas de estudo }\end{array}$ & & & & & \\
\hline & & $\begin{array}{l}\text { Tipo de espécies de aves observadas no litoral centro norte de } \\
\text { Santa Catarina }\end{array}$ & & & & & \\
\hline & \multirow{2}{*}{$\begin{array}{l}\text { Proteção da } \\
\text { natureza }\end{array}$} & Áreas dos municípios costeiros protegidos por via de leis & & & & & \\
\hline & & Proporção que ocupa cada espaço protegido por leis & & & & & \\
\hline & \multirow{3}{*}{$\begin{array}{l}\text { Áreas } \\
\text { Prioritárias para } \\
\text { a Conservação }\end{array}$} & Número de Áreas Prioritárias para a Conservação nos municípios & & & & & \\
\hline & & $\begin{array}{l}\text { Superfície relativa ocupada pelas Áreas Prioritárias para a } \\
\text { Conservação em relação às áreas dos municípios }\end{array}$ & & & & & \\
\hline & & Importância das Áreas Prioritárias para a Conservação & & & & & \\
\hline \multirow{4}{*}{$\begin{array}{l}\text { População e } \\
\text { Demografia }\end{array}$} & $\begin{array}{l}\text { Densidade } \\
\text { demográfica }\end{array}$ & Evolução da densidade demográfica dos municípios costeiros & & & & & \\
\hline & \multirow{3}{*}{$\begin{array}{c}\text { Tendências da } \\
\text { evolução da } \\
\text { população }\end{array}$} & Estimativa da população para os municípios em 2050 & & & & & \\
\hline & & $\begin{array}{l}\text { Estimativas da população com mais de } 60 \text { anos para os municípios } \\
\text { em } 2050\end{array}$ & & & & & \\
\hline & & Proporção de pessoas com mais de 60 anos em 2010 e 2050 & & & & & \\
\hline \multirow{3}{*}{$\begin{array}{l}\text { Qualidade da } \\
\text { água }\end{array}$} & \multirow{3}{*}{$\begin{array}{l}\text { Qualidade das } \\
\text { águas do mar } \\
\text { (balneabilidade) }\end{array}$} & Evolução da balneabilidade da água das praias dos municípios & & & & & \\
\hline & & $\begin{array}{l}\text { Balneabilidade da água das praias dos municípios para o ano de } \\
2011\end{array}$ & & & & & \\
\hline & & Destino final do esgotamento sanitário e resíduos sólidos & & & & & \\
\hline \multirow{6}{*}{ Riscos } & \multirow{2}{*}{ Erosão costeira } & Balanço de sedimento nas praias & & & & & \\
\hline & & Parte do litoral sujeito a erosão & & & & & \\
\hline & \multirow{2}{*}{$\begin{array}{l}\text { População } \\
\text { presente total } \\
\text { ao longo da } \\
\text { costa }\end{array}$} & População residente e população máxima nas cidades litorâneas & & & & & \\
\hline & & População presente total nos municípios ao longo do ano & & & & & \\
\hline & \multirow{2}{*}{$\begin{array}{l}\text { Catástrofes } \\
\text { naturais }\end{array}$} & Número de eventos catastróficos registrados nos municípios & & & & & \\
\hline & & Frequência de catástrofes naturais nos municípios & & & & & \\
\hline \multirow{4}{*}{ Uso do solo } & \multirow{4}{*}{$\begin{array}{l}\text { Ocupação do } \\
\text { uso do solo }\end{array}$} & Uso do solo em 2010 & & & & & \\
\hline & & Evolução do uso do solo entre 1995 e 2010. & & & & & \\
\hline & & Uso do solo em função da distância do mar em 2010 & & & & & \\
\hline & & Uso do solo em função da distância do mar entre 1995 e 2010 & & & & & \\
\hline
\end{tabular}

Observa-se que os indicadores possuem relações causais com os demais, o que permite estabelecer uma rede de relações entre esses e entre as fontes de origem e o resultado da manifestação de determinados fenômenos. 
Identificou-se que três indicadores visam analisar o estado do ambiente, e que a força motriz da cadeia causal dos indicadores é a densificação urbana, uma vez que essa possui relação com todos os outros indicadores.

Como indicadores de pressão, identificou-se a população total presente nos município, a população para o ano de 2050, a evolução do uso do solo entre os anos de 1995 e 2010. Esses indicadores evidenciam a pressões no ambiente que são responsáveis por infligir uma mudança no estado do ambiente. Relacionado ao estado estão os indicadores de natureza e biodiversidade, balanço de sedimentos nas praias e o uso do solo.

Os indicadores de impactos no modelo DPSIR são: número de eventos catastróficos naturais nos municípios; e a balneabilidade das águas do mar. Já, como indicadores de resposta identificou-se: Importância das Áreas Prioritárias para a Conservação; Proporção que ocupa cada espaço protegido por leis; Áreas dos municípios costeiros protegidos por leis ambientais.

Através das inter-relações que surgiram do sistema DPSIR é possível perceber que a densificação populacional causa uma pressão nas áreas naturais do município, causando a diminuição destas em função expansão urbana.

E com o processo de artificialização do solo, os ambientes costeiros estão cada vez mais fragmentados, o que é possível identificar mediante a análise dos indicadores de estado, como por exemplo, o uso do solo. Estes refletem ainda, em questões tais como o número de ecossistemas presentes, a proporção e o nível de presença desses no município, assim como o balanço de sedimentos e as aves migratórias na região.

A densificação populacional também contribui indiretamente com 0 aumento da carga de resíduos e efluentes nos municípios. Essa carga de contaminantes, mal gerenciada exerce influência na qualidade ambiental, principalmente no que se refere na qualidade da água. $\mathrm{O}$ que claramente pode ser correlacionado com a balneabilidade da água da praia dos municípios analisados. 
Figura 4: Relações entre os indicadores e o modelo DPSIR
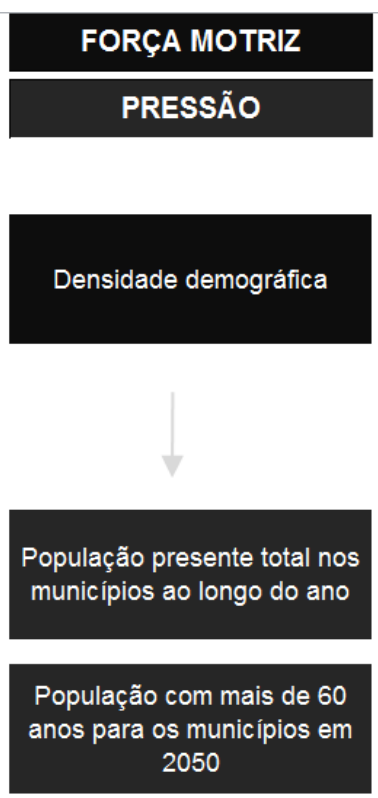

População residente e população máxima nas cidades litorâneas

\begin{tabular}{c} 
ESTADO \\
\hline IMPACTO
\end{tabular}

Proporção que cada ambiente natural ocupa no litoral

Número de indivíduos de aves migratórias observadas próximas às áreas de estudo

Uso do solo em 2010
RESPOSTA

Números de locais de prioritários para conservação

Áreas dos municípios litorâneos protegidas por tipo de áreas de conservação regulamentadas

Número de eventos catastróficos registrados nos municípios

Balneabilidade da água das praias dos municípios para o ano de 2011

\section{CONCLUSÃO}

Com a intensificação do processo de artificialização do solo, os ambientes costeiros estão cada vez mais fragmentados, o que foi possível identificar mediante a análise dos indicadores, como por exemplo, o uso do solo. Essa constatação também é refletida nos indicadores de natureza e biodiversidade, que permitem a visualização da expansão do tecido urbano em depreciação dos ecossistemas presentes no município.

A aplicação associada dos indicadores para as áreas de estudo permite a geração de um sólido embasamento para um diagnóstico socioambiental que sirva com um barômetro da sustentabilidade, estabelecendo quantitativamente medidas da dinâmica populacional, sua interação com o meio ambiente e as respostas da gestão pública.

Os indicadores elencados mostraram-se de simples entendimento, passiveis de fazer o elo de comunicação social com a população municipal, de forma simplificada e didática. 
Ressalta-se que os municípios sofrem com a especulação imobiliária, sendo um dos principais vetores de substituição de ambientes naturais (principalmente restinga e encostas de morros) por malha urbana. O sistema de indicadores proposto não contempla diretamente esse processo, contando apenas com um indicador suplementar como é o caso da densidade demográfica ou da evolução da população.

Sob essa perspectiva, indicadores econômicos poderiam ser incluídos, o que permitiria identificar se especulação imobiliária ameaça os ambientes naturais. Indicadores econômicos também podem contribuir para entendimentos sobre a melhoria de vida das populações em situação de maior vulnerabilidade, a identificação de qual o extrato social que está sendo beneficiado, etc.

Tendo como referência os resultados apresentados pelos indicadores, ficou claro que estes auxiliam no entendimento da dinâmica de uso e ocupação do solo, e possibilitam uma análise integrada da influência das atividades humanas sobre a qualidade ambiental.

Uma vez aplicados na gestão pública, estes indicadores podem apontar locais com conflitos ou com interferências nocivas na qualidade ambiental e de vida da população. Quando os indicadores são levados em consideração no processo decisório, é possível estruturar medidas estratégicas precisas para intervenções, atendendo diretamente a problemas e melhorando a eficiência da governabilidade, subsidiando inclusive, uma análise de desempenho pela administração pública e contribuindo para o controle social dos munícipes.

\section{REFERÊNCIAS BIBLIOGRÁFICAS}

ASMUS, M.; KITZMANN, D. Gestão costeira no Brasil estado atual e perspectivas. Ecoplata: Programa de Apoyo a la Gestión Integrada en la Zona Costera Uruguaya. Rio Grande, 2004.

BRASIL - Lei 7.661 de 16 de Maio de 1988. Institui o Plano Nacional do Gerenciamento Costeiro. Brasília, 1988.

BRASIL. Decreto no 5.300 de 7 de Dezembro de 2004. Regulamenta a Lei no 7.661, de 16 de maio de 1988, dispõe sobre regras de uso e ocupação da zona costeira e estabelece critérios de gestão da orla marítima, e dá outras providências. Brasília, 2004. 
CAMMARROTA, M.; PIERANTONI, I. Urban Environmental Indicators in the DrivingPressure-State-Impact-Response (DPSIR) Scheme. Convegno Intermedio SIS 2005. Società Italiana di Statistica. Università di Messina Rome, 2005.

JANNUZZI, P. M. Indicadores sociais no Brasil: Conceitos, Fontes de dados e Aplicações. Editora Alínea. 3. Ed. ISBN 85-86491-95-0. Campinas, 2006.

FATMA - Fundação Estadual do Meio Ambiente de Santa Catarina. Histórico de Balneabilidade. em:

http://www.fatma.sc.gov.br/laboratorio/dlg_balneabilidade2.php>. Acesso em 21/11/2012.

IBGE - Instituto Brasileiro de Geografia e Estatística. Censo 2010. Densidade demográfica. Disponível em: <http://www.censo2010.ibge.gov.br/sinopse/index.php? dados $=10 \&$ uf $=00>$.

IBGE - Instituto Brasileiro de Geografia e Estatística. População brasileira envelhece em ritmo acelerado. Comunicação Social. 2008. Disponível em: < http://www.ibge.gov.br/home/presidencia/noticias/noticia_visualiza.php?id_noticia=1272> . Acesso em 30 de Setembro de 2012.

MMA - Ministério do Meio Ambiente. Zona Costeira e Marinha. Disponível em: <http://www.mma.gov.br/biodiversidade/biodiversidade-aquatica/zona-costeira-emarinha>. Acesso em 15/07/2013.

MMA - Ministério do Meio Ambiente. Agenda 21 Global. Capitulo 5: Dinâmica demográfica e Sustentabilidade. Conferência Das Nações Unidas Sobre Meio Ambiente e Desenvolvimento. 1992.

MMA - Ministério do Meio Ambiente. Biodiversidade Brasileira. Avaliação e identificação de áreas e ações prioritárias para conservação, utilização sustentável e repartição dos benefícios da biodiversidade nos biomas brasileiros. Secretaria de Biodiversidade e Florestas. Brasília, 2002.

ONML - OBSERVATOIRE DU LITTORAL. Le littoral: chiffres-clés. Études \& Documents.Observation et Statistiques. Commissariat Général au Devéloppment durable. Envorioment no 32, janeiro de 2012.

PNUE - Programme des Nations Unies pour l'environnement. Indicateurs pour le Développement Durable dans les régions côtières méditerranéennes: Suivi dês recommandations de la Commission Méditerranéenne de Développement Durable Rapport final. Plan Bleu pour l'environnement et le développement en Méditerranée Centre d'Activités Régionales. Antipolis, 2002.

PROJETO ORLA: Fundamentos para gestão integrada. Brasília: MMA/SQA; Brasília: MP/SPU, 2002. 78p.

SANTUR - SANTA CATARINA TURISMO. Estatísticas e indicadores. Disponível em: < http://turismo.sc.gov.br/>. Acesso em 02/02/2013.

TISCHER, V.; POLETTE, M. Proposta metodológica de estabelecimento de indicadores socioambientais para a zona costeira brasileira. Revista Brasileira de Gestão e Desenvolvimento Regional (No prelo). Universidade de Taubaté. Taubaté, 2016. 